\title{
Enhancing Nurse Leadership Capacity in Resource-Limited Countries
}

Veronica Njie-Carr ${ }^{1, *}$, Odunola Adeyeye ${ }^{2}$, Lamin Marong ${ }^{3}$ and Francis Sarr ${ }^{4}$

${ }^{1}$ Assistant Professor, School of Nursing, University of Maryland, Baltimore, MD 21201, USA

${ }^{2}$ Clinical Nurse Leader Student, School of Nursing, University of Maryland, Baltimore, MD 21201, USA

${ }^{3}$ Deputy Director of Nursing, Midwifery and Community Health Services, Ministry of Health and Social Welfare, The Gambia ${ }^{4}$ Dean for Graduate Studies and Department Head, MSc Program, The University of The Gambia, The Gambia

\section{Abstract}

Background: Nurse leaders are essential contributors to global health and health care delivery systems. Developing and strengthening nurse leader capacity enhances quality care and improves patient outcomes so no one is left behind. Low workforce capacity leads to poor health outcomes for patients. Collaborations between institutions have been shown to strengthen nurse capacity in resource-limited countries and supplement the brain drain phenomenon. This discursive paper aims to share lessons learned from implementing a graduate nursing program to develop leadership capacity in a resourcelimited country and to discuss strategies to enhance partnerships, influence health policies, and improve global health care.

Materials and Method: Develop nurse leadership capacity through a graduate nursing program.

Results: To date, 51 students have been enrolled and 16 have successfully completed the master's program with thesis. Most of the graduates now hold top management positions ranging from middle to senior management. These nurse leaders are in charge of operations and management, programming and policy implementation. Contributions of the program is demonstrated in changes in leadership capacity exemplified in marked infrastructural and process changes in the National Association of Gambian Nurses through increased nurse involvement at the Ministry of Health level, and enthusiasm and commitment to quality care for patients.

Conclusions: Efforts to strengthen nurse leadership capacity through collaborations between developed and developing countries are essential to improve nurse leadership capacity, increase health policy engagement, and workforce retention. Workforce improvement and quality nursing services through these collaborations will strengthen nurse leadership and propagate positive health outcomes for patients as well as contribute to solving the brain drain in resource-limited countries.

\section{Introduction}

Education of nurses beyond the diploma level has been limited in resource-limited countries because of faculty capacity and the necessary infrastructure to support such endeavors [1]. As more faculties in resource-limited countries achieve doctoral education, the problem will slowly resolve, but perhaps not fast enough to address the nurse leadership shortage. Another important constraint in developing nurse leadership capacity is the brain drain of highly qualified and educated nurses who migrate from their home country to countries with higher salaries and better working conditions. Of grave concern is that nurses fail to return to contribute to the development of their countries, which negatively impacts the health of patients and health care delivery systems. To mitigate the brain drain while addressing quality patient care in these countries, collaborations between nurse leaders in developed countries and aspiring leaders in resourcelimited countries become paramount for sustainable development [2] and global health.

Developing and strengthening nurse leader capacity is an important component in developing health and health care infrastructure in resource-limited countries. Collaborations could reduce the increasing burden of disease through advanced nursing education focused on evidence-based practice for sound clinical decisionmaking and positive patient outcomes [3]. Nurse's commitment in research, plays a crucial role in the strengthening of evidence-based nursing practice [3]. Nurse leaders are important contributors to global health and the health care delivery systems in every country as they are in unique positions to influence policies that would enhance quality care and positive patient outcomes. health care.

\section{Background} Njie-carr@son.umaryland.edu

\section{Publication History:}

Received: June 30, 2016

Accepted: September 07, 2016

Published: September 09, 2016

\section{Keywords:}

Collaboration, Health Policy, Nurse Leadership Capacity, Nursing Education, The Gambia Therefore, with strong nurse leadership, potential constraints will be mitigated and opportunities optimized. Qualified nurse leaders who have the expertise and knowledge to develop and maintain sustainable health care infrastructures in resource-limited countries are needed [4]. Collaborations between institutions in developed and developing countries have shown positive results [5] and these efforts should be replicated and strengthened for sustainable global health and health programs. Training of nurses at the doctoral level would increase research and innovation in nursing, enhance capacity of universities to supervise postgraduate students, increase the number of trained nurse leaders at the doctoral level and enhance capacity for global competitiveness [6]. The aim of this paper is to share lessons learned from implementing a graduate nursing program to develop leadership capacity in a resource-limited country and to discuss strategies to enhance partnerships, influence health policies, and improve global

Building nurse capacity is a global challenge given the high turnover

"Corresponding Author: Dr. Veronica Njie-Carr, School of Nursing, University of Maryland, Baltimore, MD 21201, USA, Tel: 1-410-706-4808; E-mail:

Citation: Njie-Carr V, Adeyeye O, Marong L, Sarr F (2016) Enhancing Nurse Leadership Capacity in Resource-Limited Countries. Int J Nurs Clin Pract 3: 200 doi: http://dx.doi.org/10.15344/2394-4978/2016/200

Copyright: (C) 2016 Njie-Carr et al. This is an open-access article distributed under the terms of the Creative Commons Attribution License, which permits unrestricted use, distribution, and reproduction in any medium, provided the original author and source are credited. 
rate in workforce personnel in low-income countries. The phenomenon is directly influenced by inadequate compensation, poor working environments, limited opportunities for professional development and progress to better career options [7]. Additionally, nurses are not provided with opportunities to make important decisions at the national or international levels that influence infrastructural and health policy changes [8]. Furthermore, migration of nurses has widened the turnover gap [4]. As nurses form the majority of global health care professionals [4] and in most countries are the only clinicians available to provide direct patient care, there is dire need to strengthen nurse leadership capacity. Limited resources in these countries increase the constraints experienced by nurses to progress and affect change [4]. Developing nurse leadership capacity has to start with educating nurses to strengthen their position and leverage capacity. One effective way is by collaborating with nurses in developed countries to work closely for sustainable global health [5, 9]. Building capacity and increasing qualified nurse leaders globally can help bridge the gap in the health care workforce in low-income countries while providing needed support, personal, and professional motivation [1,8]. Most importantly, perhaps, it will enhance nurse leadership capabilities that will be poised to contribute to important health care decisions that will positively affect patients outcomes [2, $4]$.

While capacity programs have been implemented in the areas of practice and research, more work is needed to develop and strengthen nurse leadership through graduate level education in resourcelimited countries. Nurse leaders could contribute to strong health infrastructure, advocate for patients, lead in the implementation of evidence-based practice, and influence health policies that have important implications for nursing practice, research, and education. Therefore, programs must continue to be developed that address this growing need for nurse leaders who would make important decisions that impact health outcomes of patients.

The World Bank reports that universities in Africa are limited in research expertise related to innovation and problem solving [7] and thus present enormous challenges for the development of nurse leaders. Graduate and postgraduate training are pathways for research and leadership capacity development and through which nurses can enhance competence to engage in research, compete for funding, and implement evidence-based practice [3].

Few nurses in resource-limited countries have an academic degree beyond the basic nursing program, such as countries like The Gambia. The poor infrastructure at universities in Africa [7] is a result of multiple intersecting factors such as the political will to ensure that policies are enforced from the leadership, lack of staff motivation, dissatisfaction with work environments [8] resulting in limited ability to work strategically to influence health policies. Thus, nurse leader burden could be eased through global collaborations $[9,10]$. Through these collaborations, nurse leaders will increase the implementation of evidence-based practice, better quality of care, and enhance participation in decision-making on health systems and policies [1]. Through developing graduate-level education in resource-limited countries, nurse leaders will influence health and health care in these countries for optimal global health outcomes. This discursive paper addresses lessons learned from implementing a graduate nursing program to develop leadership capacity in a resource-limited country and discusses strategies to enhance partnerships, influence health policies, and improve global health care.

\section{Materials and Method}

Limited availability of doctorally-prepared faculty in The Gambia inspired collaborations between the nursing department head and a faculty in the United States. Through multiple conversations and planning, the master's degree in nursing (MSc; same as MSN in some countries) was established in 2011 to begin developing nurses at the graduate level. Prior to this, a baccalaureate (BSc; same as BSN in some countries) in nursing program was started at the same time that the University of The Gambia was instituted in 1999. Collaborators shared information and documents relevant to the MSc curriculum including the MSc conceptual framework, mission, outcome objectives, and other related information. Courses appropriate for an MSc degree were discussed and content prepared to improve the program. Given that practicing nurses enrolled in the program worked in community health and were interested to continue in that line of work, the MSc program was tailored to reflect this area of need for the first few cohorts. In addition, other available tracks include roles in nursing education and management. Students are required to complete a research thesis addressing education or clinical research problems in The Gambia to fulfill MSc degree requirements and successfully complete the program. Students enrolled full-time in the program complete it in 2 years including summer months.

\section{Results}

The first cohort of students in the MSc program were enrolled in the summer of 2011. As of summer 2016, 51 students have been enrolled with high retention rates ranging from $81 \%-100 \%$. Sixteen students have successfully completed and graduated from the program. Students dropped out of the program because of extenuating circumstances such as illness $(n=2)$ and financial constraints $(n=4)$ demonstrating the value and perceived benefits that students have in the program and suggesting the critical need to sustain the program. Students come from diverse sectors including clinical practice, education, and management and comprise of unit heads, matrons (same as managers in other countries), regional program directors, academics, and senior nursing officers.

\section{Challenges and Lessons Learned}

\section{Program graduates}

Graduates from the program returned to their previous employment and secured leadership positions while some pursued overseas opportunities for further education. Additionally, graduates of the program have contributed to marked improvements in the National Association of Gambian Nurses organization's infrastructure, increased nursing's involvement at the health policy level, and increased enthusiasm and commitment to provide quality care for patients. In terms of leadership positions from these cohorts, most of the graduates now hold top management positions ranging from middle to senior management. These nurse leaders are in charge of operations and management, programming and policy implementation. Most importantly, perhaps, graduates from the MSc program return to be leaders and contribute to making important changes in the clinical practice, education, and research areas. For example, most government-run health care facilities in The Gambia fail to provide staff with job descriptions at time of employment, provide professional development opportunities, or follow policies to discipline staff when patient care is jeopardized. Nurses are now taking the lead to implement changes in different areas of practice. 
One of the authors (LM) was promoted to middle management and was in charge of the nursing, midwifery and clinical services of two health regions in The Gambia before being promoted to Deputy Director of Community Health Services (comparable to a US Health Commissioner).

\section{Challenges}

Limited availability of resources in developing countries tantamount to numerous challenges that students must overcome to be successful. In The Gambia, the challenges constitute three broad categories: (a) infra-structural and resource challenges that are unique experiences for students in developing countries; (b) professional challenges that are experienced in some countries; and (c) personal challenges experienced globally. Segrott and colleagues [1] in a review of the literature including 10 studies addressing research capacity in national and international studies found similar constraints' that were conceptualized as "material constraints, organizational contexts, and the changing roles and expectations of nurse educators" (p. 640). These authors highlighted the need for global capacity building as the roles of nurses continue to evolve and expand. The expanding role of the nurse is also captured in the WHO report [2].

\section{Infrastructural challenges}

Challenges related to infra-structure include internet connectivity, uninterrupted available electricity, and access to peer-reviewed journal articles. For example, for graduate students to integrate theoretical and empirical findings to apply concepts and processes and to integrate information in papers and presentations, they require access to current peer-reviewed papers to substantiate scholarly discussion. However, given the inadequacy of the uninterrupted internet connection and consistent availability of electricity, students for the most part are unable to access relevant studies to inform their work causing major challenges that sometimes leads to frustration, anger, and stress. Even though the University subscribes to HINARI [11], the WHO-sponsored access to academic databases, students are unable to access it because of slow wifi connectivity or lack of electricity affecting uninterrupted service. Students access journal articles written in English given that English is the official language in The Gambia. So far, problems related to communicating in English have not been identified. In addition to connectivity issues, downloading journal articles using data card (provides internet connection with a charge) could cost thousands of dalasi (D1 = \$43U.S.). These mundane albeit essential services that students in developed countries take for granted are major constraints in resource-limited countries. In most cases, the visiting professor retrieves relevant journal articles prior to leaving the United States and shares them with students to support their work. Some students relied on continuous connectivity at their places of work to complete assignments because of poor internet connection at home and other locations. As one student aptly noted, “... I relied on the facility internet in my office at the facility [because] electricity is more reliable at the facility than home. Even at the facility, moments of poor internet access and power cuts have resulted in failure to meet assignment deadlines."

Finding classrooms optimal for teaching instruction for students is also a major barrier particularly when other programs such as the medical and BSc classes are held simultaneously. Students attend classes at different locations sometimes up to approximately eight miles away from the main campus. The department head of the nursing program arranged to build classrooms in a major teaching hospital premises to leverage the continuous electric supply. Even though this move is some progress, internet connectivity continues to be a major problem. Shishani and colleagues [4] discussed the use of a Supercourse, which is a global library that provides students with high quality educational materials to build education capacity and inform practice. This paper, however, failed to address the issue of connectivity in resource-limited countries. In spite of these constraints, Gambian students continue to persevere to ensure that they successfully complete the MSc program.

\section{Professional challenges}

Instituting granular changes that reflect improvement in intellectual capacity through advanced nursing education is another major constraint. When class discussion revolves around conceptualizing strategies to change staff nurse behaviors to improve professionalism and optimize positive patient outcomes, students express willingness and commitment to pursue the necessary changes that would be effective. However, very quickly their excitement for what is possible turns to consternation and frustration because of the limited power they feel they have that might prevent their ability to apply the strategies in practice. Some students shared stories of how some of the upper level managers failed to enforce hospital policies to address issues of professionalism and unsafe patient care practices. Additionally, the limited availability of the necessary resources such as working sphygmomanometers, glucometers, etc. makes the situation worse and overwhelming. For example, a robust discussion ensued when staff absenteeism and tardiness were addressed. Their frustration was clear yet they are unable to act independently (or with top managers) to affect the changes necessary. Students expressed how it remains an enormous problem because staff nurses and low level management efforts are stifled and the General Orders (GO) that stipulate policies and procedures for such actions are not being enforced by top management. These challenges have resulted in disinterest and reduced confidence that anything would work thus contributing to the status quo. Open discussions through sharing of stories elucidated that absenteeism and tardiness were pervasive in all clinical areas across the country. They realized, however, that they could support each other to make the change happen. Students expressed that with the new information, they can galvanize their staff to support their work and empower them to lead the initiatives for change. It is encouraging to witness students' renewed self-confidence and transformation with the determination and motivation that something could be done and they can take the lead to facilitate the change process. Students were cognizant of the reality that the Nursing Management and Leadership Concepts course prepared them for leadership positions and roles to lead changes in nursing and the health care system.

\section{Personal challenges}

From a global perspective, students experience personal challenges related to multiple intersecting factors such as family, financial, and/ or professional roles. Students in this MSc program experienced competing priorities that were difficult to reconcile albeit motivated to pursue the degree. They have children, husbands, wives, and other significant others that need their time and support. Additionally, some of the students had been out of academia for years and had difficulty transitioning from a practitioner to a full-time student role. This latter issue has prompted the MSc department head to modify the MSc program entry requirements to students who completed a $\mathrm{BSc}$ in nursing and are interested in enrolling in the MSc program. 
Another barrier is the challenge students' encounter to pay for tuition and fees. It costs D160K (Dalasi; D1 = \$43) for two years of full-time course work including master's thesis on a research project. Therefore, students must obtain sponsorship through the Ministry of Health or other sources to finance their studies and still maintain fulltime work to support self and their families.

\section{Discussion}

\section{Nurse leadership}

Nurses in resource-limited countries can propagate and sustain quality patient outcomes through leadership roles and participation in framing health policies and important health care decisions. To influence this outcome, nurses must obtain advanced degrees so they can contribute to influencing clinical practice, research, and policy. The brain drain has contributed to the negative impact on the availability of qualified nurses in resource-limited countries. Collaboration with nurses in academia in developed countries will help minimize and eventually eliminate the burden, and most importantly, contribute to global health [9] by optimizing safe quality patient care. Spies and colleagues [10] reported similar partnerships and found benefits related to opportunities for development of clinical skills, research capacity and augmenting service-related capacity. Important collaborations have been established between partner institutions across the globe and their sustainability is critical to promote global health. Additionally, these efforts will contribute to strengthening nursing education through the development of nurse leadership capacity in resource-limited countries.

Few studies have adequately evaluated collaborations between developed and developing countries to determine long-term outcomes [10] and to evaluate if practices need to be modified for efficacy, effectiveness, and sustainability. Another important need is increasing funding sources through fellowships and scholarships that would help continue to develop nurses for optimal performance in their home countries. Another perspective is that developing nurse leadership capacity is a moral obligation given its profound effects on personal, professional, societal, and health care policies. Government and non-governmental organizations have important roles to play to increase these important collaborations. The annual Global Nursing Leadership Institute through the International Council of Nurses (ICN) is an example of organizations that are supporting such efforts [12]. Also, other organizations such as the Sigma Theta Tau International Honor Society of Nurses (STTI) have Global health initiatives [13], which could be leveraged to increase collaborations. However, nurses in resource-limited countries are unaware that these resources are available. Therefore, providing access and linking them to these resources must be deliberate and strategic. A study conducted by Zuyderduin et al., [14] noted that approximately $80 \%$ $(\mathrm{N}=217)$ nurse participants reported the value of nurse organizations through memberships. Nurses reported benefits such as increase in providing quality patient care and development of practice skills. Additionally, universities in the US have offices dedicated to global work that leverage student exchange visits. One challenge of exchange programs is funding for visiting professors and students. Students in resource-limited countries encounter financial challenges that make it difficult for them to visit other countries to learn, network, and acquire mentoring opportunities. Therefore, funding sources could be helpful in sustaining long-term endeavors through financial support to resource-limited countries. Through these exchange visits, nurse leaders could enhance opportunities to engage in activities that will inform practice upon return to their home country. Exchange visits will also provide opportunities for real-life experiences, one of the best models to provide hand-on experiences and lasting impressions.

\section{Conclusions}

Through collaborations with international academic institutions, resource-limited countries have the opportunity to develop strong workforce of nurses to contribute in leadership positions in diverse health sectors. In turn, it will potentially mitigate the brain drain and provide opportunities for nurses to stay in their home country to practice. It is important to note that most of the studies and papers reviewed in writing this manuscript were focused on practice, education, and research capacity development. Through the strengthening of these sectors, nurse leadership capacity will be enhanced. This suggests that very few papers have addressed global nurse leadership capacity building and ours is one of the few papers on this important topic.

\section{Competing Interests}

VNC is a member of the Editorial Board. The authors declare that they have no competing interestes.

\section{Author Contributions}

VNC contributed to the conception, design, drafting, and final versions of the paper. OA contributed to the literature search and review and draft versions of the paper. LM contributed to writing the draft and final versions of the manuscript. FS was involved in writing the drafts and final versions of the manuscript.

\section{References}

1. Segrott J, Mclvor M, Green B (2006) Challenges and strategies in developing nursing research capacity: a review of the literature. Int J Nurs 43: 637-651.

2. World Health Organization (2016) Nursing and midwifery - WHO global strategic directions for strengthening nursing and midwifery 2016-2020.

3. Sheehan A, Comiskey C, Williamson C, Mgutshini T (2015) Evaluation of the Implementation of a PhD Capacity-Building Program for Nurses in South Africa. Nurs Res 64: 13-23.

4. Shishani K, Allen C, Shubnikov E, Salman K, Laporte RE, et al. (2012) Nurse educators establishing new venues in global nursing education. $J$ Prof Nurs 28: 132-134.

5. Njie-Carr V, Kalengé S, Kelley J, Wilson A, Muliira JK, et al. (2012) Research Capacity-Building Program for Clinicians and Staff at a Community-Based HIV Clinic in Uganda: A Pre/Post Evaluation. J Assoc Nursin AIDS Care 23: 431-441.

6. Comiskey CM, Matthews A, Williamson C, Bruce J, Mulaudzi M, et al. (2015) Scaling up nurse education: An evaluation of a national PhD capacity development programme in South Africa, in the context of the global shortage of nursing graduates. Nurse Educ Today 35: 647-652.

7. The World Bank (2009) Accelerating Catch-up: Tertiary Education for Growth in Sub-Saharan Africa. Washington DC: The World Bank

8. West F, Homer C, Dawson A (2016) Building midwifery educator capacity in teaching low and lower-middle income countries. A review of the literature. Midwifery 33: 12-23.

9. Amieva S, Ferguson S (2012) Moving forward: nurses are key to achieving the United Nations Development Program's Millennium Development Goals. Int Nurs Rev 59:55-58.

10. Spies L, Garner S, Prater L, Riley C (2015) Building global nurse capacity through relationships, education, \& collaboration. Nurse Educ Today 35: 653-653. 
Citation: Njie-Carr V, Adeyeye O, Marong L, Sarr F (2016) Enhancing Nurse Leadership Capacity in Resource-Limited Countries. Int J Nurs Clin Pract 3: 200. doi: http://dx.doi.org/10.15344/2394-4978/2016/200

Page 3 of 3

11. HINARI (2016) Hinari access to research for health programme.

12. Blaney $P$ (2012) Senior nursing leadership - capacity building at the global level. International Nursing Review 59: 40-47.

13. Sigma Theta Tau International (2016) STTI's global initiatives.

14. Zuyderduin A, Obuni JD, McQuide PA (2010) Strengthening the Uganda nurses' and midwives' association for a motivated workforce. Int Nurs Rev 57: 419-425. 